\title{
Co-production towards just urban transformation Two different ways in Budapest, Hungary and in Sassari, Italy
}

\author{
Zsófia Anna Ghira, University of Sassari, DADU, Italy
}

Valeria Monno, Politecnico di Bari, Italy

\begin{abstract}
Innovative participatory processes, such as co-production is based on the creativity and the inclusion of participants. It is able to transform social relations, and can have significant positive impacts on urban transformations, therefore it is supported by local governments. Although through co-production citizens can have significant impact on decision-making and transformation, on the other hand, scholars argue that state-initiated processes can be the motors of institutionalization of inequalities.

Taking spatial justice and its theoretical background, our paper offers a critical perspective toward co-production, as deployed in urban planning and policies, by focusing on two cases from different cities. Within the case of Budapest an urban regeneration programme is introduced in the most deprived neighbourhood of the city. In the other case we study the programme Crossing Cultures (Intrecciare Culture) in Sassari, Italy, that is a co-productive initiative is aimed to revitalize the historical centre of the city. The paper answers how/if co-production can contribute to spatial justice, to the fair distribution of socially valued resources in different places.
\end{abstract}

\section{Keywords}

spatial justice; governance; co-production; transformative change, regeneration

\section{Introduction}

Different case studies from various places and scholars argue that through co-production social relations can be transformed, while significant positive impact can be created on urban transformations. In many cases co-production works as a win-win process between the state and the grassroot-organisations, where all the parties can make benefit. Thus, public bodies and local governments are keen on support these initiatives. However, many scholars use criticism, such as co-productive processes can maintain the status quo of the current power relations, not giving enough space to reach bigger changes in urbangovernance structure.

The structure of the paper begins with a literature overview on co-production and spatial justice. The methodology is based on two case studies coming from different countries in Europe. The first from Sassari, Italy, while the second from Budapest, Hungary. The common characteristics in the cases are the aim of the initiatives and the co-productive methodology used. In both cases the principal aim of the public body was to find solutions that can counteract the urban decay, create better living conditions, and relations between residents, institutions and the space. For that, co-productive method was used, involving grassroots organizations and NGOs. The research examines how/if co-production can contribute to spatial justice in different environments, moreover, reflects on the deficiencies of co-production in the light of spatial justice. 


\section{Co-production towards spatial justice}

\subsection{Co-production}

The concept of co-production comes from Elinor Ostrom, as she underlines the synergy that collaboration between state and citizens can result in her work (Ostrom 1996). The synergy comes from the complementary knowledge, which the two parties have. It construes the relation between state and citizens and the joint production of public goods and services. With numerous case studies was it illustrated, how small-scale co-productive interventions were able to have crucial impact on urban policies and power relations (Brandsen and Pestoff, 2006). On contrary, Boivard (2007) argues that there is a gap between project-level and policy-level activities when it is spoken about co-production. Thus, even if there is potential to form the practices into a policy-level formula e.g., into a strategy, in small cases went it like that. Pieterse says, due to the rigidity and the hierarchic structure of state bureaucracies, hardly can they adapt innovative solutions (Pieterse 2008). Co-production surely has advantages providing the needed services or products, moreover, it guarantees certain synergy not just between state and citizens but also between the movements and their engagements on the day to day needs of the society and also related to political inclusion and redistribution (Joshi and Moore 2004).

However, the self-organization of these residents is hardly considered as a way in which they can express their interest, controversially, Mitlin (2008) says, it is more probable to find cases where political influence has tried to arrive or has arrived from the top to down in this way. Vulnerable social groups in urban context struggle with many consequences of lack of resources. Thus, they have to make alliances and relations with more powerful structures such as local government, national state in order to get their interests deputized at a higher level. Some scholars speak about the risk, that even if they might seem to be innovative, state-initiated participatory urban-governance processes can act as accelerators of the institutionalization of inequalities and the current power-relations (Cornwall 2008; Lemanski, 2017). Bringing this logic into the field of co-production, it can be translated as organizations that have fruitful network relations with public bodies can be prioritized compared to small-scale initiatives that highly can represent the same power as the first. Therefore, the capacity of participation for the vulnerable groups in the co-production is not equal comparing it with powerful groups, which results to the uneven distribution of power, to injustice.

\subsection{Spatial justice}

The phrase justice and within social justice has been explained in many different ways. In terms of spatial dimension and spatial justice, the uneven link between social relations and space is understood. Edward W. Soja in his book Seeking Spatial Justice speaks about the relevance of spatial justice, however, he does not give an exact definition of it. Thinking about space, however, has changed in the past 50 years. One of the breakthroughs was the book Social Justice and the City by David Harvey in 1973, in which he deepened the social science foundations of geographical thinking. The access, the right to use, the power on space has developed a critical element, that has led to analyse justice relations in society (Harvey 1973). In terms of spatiality, the new type of concept of space, which takes into account not only the material characteristics of space, but also departs significantly from physical reality. This makes it possible to understand the concept of social space as a complex social 'product', the social lived and consciously shaped by the society, where space is not merely a 'frame' of events, but a complex system of influencing forces and factors (Lefebvre 1991). Said that, space has become a component, that actively forms the everyday life, including the most aspects of it, such as economic development, or international politics, overall, the production of justice and injustice. Soja distinguishes endogenous and exogenous unjust relations, where in the case of the first, the emphasis is given to the role of local level, the uneven use of space that comes from the autonomous decision-making process. While in exogenous cases, due to a dominant political power, cultural repression access to space is organized unfairly. 
Soja also stands for the dialectical relationship between space and the society, where nor space neither society is on a higher level than the other. Regarding justice, he uses the equity-based concept of Rawl, as well as the characteristics of the enlightened just society, such as liberty, independency, equity, democracy, civil rights (Rawl 1997). Furthermore, the equal distribution of resources, opportunities is among the basic human rights. However, according to Soja's approach, it is necessary to concentrate on searching coalitions where the realistic objective is not greater equality between opposing social groups, but to seek a more just situation (Soja 2010).

\section{Comparative case studies}

In the paper two separate cases will be presented, and in the framework of these cases we were searching for the same: whether to-down initiated co-productive processes can contribute to the creation of spatial justice. In the case of Sassari during the programme we used a participant observer methodology, while in Budapest it is an ex-post analyses, where qualitative interviews were used.

\subsection{Crossing Cultures - a programme for the revitalization of the historical centre of}

\section{Sassari}

Sassari is the second biggest city of Sardinia, with a population of 130000 . The historical centre of the city can be described with a deurbanization process, which has started in the sixties. Residents have commenced to move to the outskirts of the city from the highly-dense urban centre. With the move-out of people, different urban functions have disappeared too. The phenomenon caused an urban decay, social segregation and a strong social degradation. Nowadays the historical centre does not give space to daily social interactions, the once flourishing streets with historical and artesian shops are mostly closed. The state of the buildings does not let the residents to have decent living conditions, that also strengthened the abandonment of the neighbourhood. According to the Detailed Plan of Sassari (Piano Particolareggiato) there are 199 problematic buildings in the historical centre, from which 122 are ruined, 56 are with the risk to be abandoned, 21 are among abandoned and ruined.

Thinking about the regeneration and the future of the historical centre of Sassari dates back to the sixties, when the abandonment process has begun. However, so far there was not a programme that could reach a change on the current processes. According to Maciocco et al. it is because these initiatives have not followed a holistic approach and only concentrated on the physical regeneration of space, ignoring the social context (Maciocco et al 2018)

"Intrecciare Culture" - Crossing Cultures is an invited initiative financed by the Ministry of Cultural Heritage and Activities, a project, that aims to counteract the previously introduced urban decay. On contrary to the previous projects, it gives special emphasize to the residents living in neighbourhood, and intents to valorise the colourful cultures represented in the most deprived part of the historical centre. Through co-production the project makes urban spaces, such as the nearby territories of the school more liveable, while at the same time creates bonds between the yet isolated inhabitants. The focus of the project is the School of San Donato, different laboratories and events are organized there, creating with this a more welcoming environment for the pupils and reducing school dropout.

The project has started in November 2019 finished in June 2021, and the Covid pandemic had a harmful impact on it. The initiative consists of six types of laboratories:

- intercultural cooking course,

- story-telling events for women,

- photography course focusing on the values of the historical centre, 
- open-air theatre,

- physical revitalization of urban spaces,

- cinema nights.

\section{Creation of community}

A strong advancement of the project is the links and bonds that have been created thanks to it among the residents of Sassari. Dwellers living in the historical centre could interact with ones living outside, moreover, immigrant people coming from different cultures could show the relevance of their diversity. Furthermore, for many residents living in the outskirts of the city was a new return and reexploring of the historical centre. Creating horizontal links inside of the community allows to abolish perceived fears regarding the space and the unknown. The experienced we gained during the operation of the project shows us that many dwellers have not stepped into the historical centre for a long time. The various laboratories, such as the cinema nights gave them the opportunity to face with the realty of the space and people living there. This progress gives the opportunity of future grassroots initiatives, as a community with strong cohesion and stronger social capital is one of the keys of the empowerment.

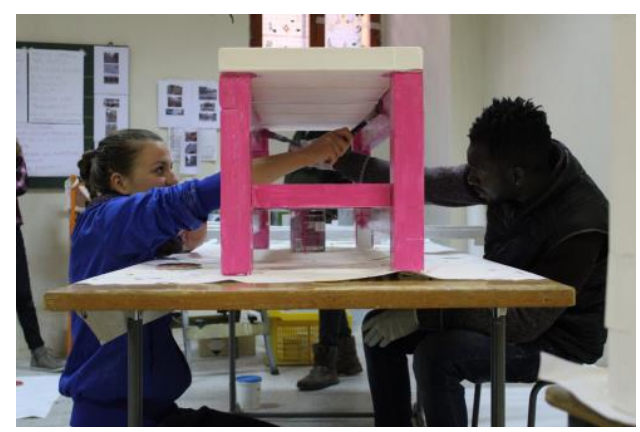

1. Figure: Participants in the rehabilitation of the urban space sub-project

\section{Participation}

Each sub-project of Intrecciare Culture has been undertaken with the active participation of residents in Sassari. Thus, the result of the projects is a common one, on which all participants have worked, and the operation has been smoothly. However, the framework, the planning phases of the project, such as the definition of the sub-projects, and the way of organization was entirely decided by the association who find out the project. They gave limited space to such creativity of the residents, there was no place to express individual ways for getting closer to the historical centre. It results also from the financial background of the project, as everything had to been organized and decided in order to gain resources for the implementation.

\section{Relationship between public bodies and dwellers}

The project directly did not unlock a special relation between the local government and the dwellers. However, the School of San Donato, the institution of the one of the most deprived parts of the historical centre of Sassari has played a significant role of the project. It gave place to more laboratories, moreover, the courtyard of the school has been renewed and made more liveable for the children. The commitment of the headmaster attracted many different personalities and contributed to the diversity of the participants.

\section{Relevance for the future}

During the implementation of the different sub-projects determining relations were made among dwellers coming from different social and economic background, between migrants and the local community. With the valorisation of such diversity, and with the supporting of soft projects dynamic sense of belonging can be created. It also promotes social inclusion and opposes gentrification. Thus, 
such interventions can have a significant progress on community-building and building both horizontal and vertical bonds, that can result in stronger advocacy too.

\subsection{Magdolna Neighbourhood Programme - urban revitalization in the most deprived neighbourhood of Budapest}

Budapest is the capital city of Hungary with 1,7 million inhabitants. The historical happenings, the transition to market economy in 1989 has fundamentally changed the way of operation in the city, moreover resulted important urban transformations. After the political change, the investors' interest was renewed, and Budapest gave place for a set of new constructions and interventions.

The introduced programme took place in the $8^{\text {th }}$ district of Budapest, in Józsefváros, which is one of the most deprived neighbourhoods of the city. This "title" can be proofed by several indicators regarding the housing conditions, social, environmental, economic status, or by the criminality rate. It was initiated by the local government of Józsefváros, and financed by a Józsefváros, Budapest and a private bank. Even if the planning process of the program has started much earlier, the first steps on the field have been made in 2005, starting with it the first phase of the Magdolna Neighbourhood Programme (MNP). In total there have been three phases, the first from 2005 until 2008, the second from 2008 to 2011, while the third from 2013 to 2015. The last one was partially financed by the ERDF (European Fund for Regional Development). The interventions went hand in hand with another development project in the district, the Corvin Promenade project. Even though that had completely different goals and path, meaning satisfying neoliberal expectations, it is said, that without the financial resources that were gained, the local government would not have been able to manage the MNP.

The main goals have been

- improving the life conditions of the inhabitants,

- creating social cohesion and inclusion,

- decrease social problems such as deprivation, poverty, uneven distribution of resources, segregation,

- using participatory processes, involving different ways of thinking,

- $\quad$ paying special attention to the most vulnerable groups

in a co-creative method, involving NGOs from the beginning of the program.

In the framework of the MNP numerous houses were renovated with the active co-production between the residents and the local government. In parallel, public spaces were regenerated with public participatory approach. The qualitative interviews conducted, the personal field visits and the analysis of the current status of the Józsefváros' society helped us to understand in which way the co-production between the state and the community contributed to spatial justice. We interviewed local NGOs, organizers of the programme, residents. For the evaluation we used fundamental aspects of transformative practices, as an evaluation framework, such as distributive matters, relationship between local government and dwellers, creation of community, relevance for the future and empowerment.

Even though this paper does not aim to introduce the operation and the background of MNP, for the better understanding we found necessary to speak some words about the status of the society in Hungary when the programme has started. The Hungarian society still brings the signs of the dictatory political system that was on power for long decades. Right after the political change, people had lack of trust in each other, while at the same time as there was not present the culture of credible interactions 
between the government and citizens. Thus, MNP had to first deal with the downside that the political, historical and spatial context delivered.

\section{Distributive matters}

As marked above, the political situation is a crucial element in the programme's life. After local government elections in $\mathbf{2 0 0 9}$, there has been a change in the political power. From then on, a right-wing party was on a power, that has changed the direction and the intentions of the programme, and the local government's commitment has turned into more neoliberal goals. The interviewed persons agree with one voice, that the change of the mayor was a critical point in the programme, that has completely changed its focus. Some says, that the responsible group (Rév 8) entirely lost its credibility, due to the fact that the new mayor did not give financial resources for the previously accepted interventions.

\section{Creation of community}

Even though in the framework of the programme a community centre has been renewed, there are little signs that certain community has been built among the dwellers. The community centre was not able to attract residents, neither to be a ground, where people with similar interests can create groups. The coproduction did not result strong bonds between the different social groups. However, according to the interviews, a semi-political group has grown out among the people who were interested and sensible for the values represented by MNP. These people were not directly involved into the programme, yet found each other and created a group, that today gives the mayor for the neighbourhood. They say, are keen on representing the most vulnerable groups in the local political level.

\section{Participation}

Regarding public participation in the planning of the public spaces, such as Teleki Square or Mátyás Square, there is a consent, that things did not go ideally. The asked persons mostly agree that the organizers were not aware of the exact method to choose to avoid dominant groups to lead the process. According to an interviewed person: "There was a lack of knowledge of how not the process to be dominated by local fascistoid individuals, intensely pro-police residents, not about them. These people's aim was how to prevent those poorer than them from using the public space. Public participation in placemaking is a learning process, not a matter of good will."

\section{Relationship between local government and dwellers}

Surely one of the most significant progresses of the programme is the improved relationship between local government and dwellers. There is a continuous communication between the parts, also the most vulnerable groups feel empowered to turn to and ask from the local government in case they are interested to. However, according to the one interview, the programme could have reached higher advancements too: "The impact is much smaller than it should have been or would have been. The programme did not continue as it started. It also reinforced the rather negative attitudes of the poorest. This was due to the failures that occurred, such as the change in the political power in 2009, the lack of involvement of crucial NGOs, mistaken way of involvement of the poorest groups."

\section{Relevance for the future}

Regarding the impact of the programme on the current and future status, it is difficult to separate the progress that has been reached thanks to the programme, as many complex elements contribute to it. However, analysing the current status of the society, and especially the political party on the local power surely represents the initial perspective of MNP. The programme left a huge impact on the society with all its achievements and failures. It emphasizes that co-production cannot be viewed as a replacement for other participatory modes of contact with local government. Citizens' engagement and participation that is more autonomous, independent, and critical must be recognized as essential for democracy in more just urban change processes.

\section{U isocarp}




\section{Research outcomes}

In MNP, the co-productive model allowed low-income groups and individuals to participate, even if they were not given the opportunity to act as a community. Depoliticization was aided by the top-down coproduction framework. Local planners and government heavily influenced the content and manner of coproduction in both the case of Budapest and Sassari. As is customary, participation was limited to NGOs active in the creation and administration of public areas on the program's periphery. Citizens were hardly involved in project planning; therefore, they were unable to effectively express their interests and organize their action priorities. As a result, co-production maintained unequal power relations while opposing a more profound shift in the structure of urban injustice.

MNP also emphasizes how co-production is very adaptable to shifts in the political system and aspirations at the national and local levels. New political ideas can simply rewrite previously stated contents and goals of programs through co-production, without igniting any serious debate.

The Magdolna project appears to emphasize that co-production is more about empowering people than it is about forming self-organizing communities. It influenced low-income households' self-awareness and created the prospect of a bilateral relationship between local government and residents. It appears to increase individual self-awareness and the ability to act to improve one's own living circumstances.

On the contrary, the case of Sassari bigger achievements in the community-building than in empowering individuals. Being an invited project, has many similarities with the MNP such as regarding the exclusion of inhabitants in the project planning phase. Even if the project was not dominant enough to have groups formed thanks to it, it has surely improved the daily interactions between residents in and out of the historical center of Sassari. However, the project did not result to be transformative.

Co-production -as the two cases show- is not particularly oriented to generate structural change in the neoliberal production of unjust urban transformations. It does not promote autonomous and critical forms of citizen engagement. The process misses the vision, the perspective of spatial justice as it is defined by Soja and it was not able to get any significant result, because it was not concerned with spatial justice.

\begin{tabular}{|l|l|l|}
\hline $\begin{array}{l}\text { Creation } \\
\text { community }\end{array}$ & $\begin{array}{l}\text { Sassari } \\
\text { mostly horizontal relationships allow } \\
\text { the participants to generate a more } \\
\text { livable space. }\end{array}$ & $\begin{array}{l}\text { The principal method in which } \\
\text { the programme aimed to create } \\
\text { community did not work } \\
\text { sufficiently. However, as a side- } \\
\text { effect, a political group has } \\
\text { grown up among residents in } \\
\text { Józsefváros, who were } \\
\text { interested of the values that the } \\
\text { programme represented. From } \\
\text { 2019 the mayor of the local } \\
\text { government comes from this } \\
\text { group. }\end{array}$ \\
\hline Participation & $\begin{array}{l}\text { The framework of the project is } \\
\text { already planned when participants join } \\
\text { to it, thus there was no real } \\
\text { participation in that phase. Specific } \\
\text { details of each sub-project can be } \\
\text { decided by them. Within these, a }\end{array}$ & $\begin{array}{l}\text { Public participation in the } \\
\text { rehabilitation of the public } \\
\text { spaces worked out with limited } \\
\text { efficiency. It rather was } \\
\text { dominated by a loud minority, } \\
\text { while the common interest could }\end{array}$ \\
\hline
\end{tabular}




\begin{tabular}{|c|c|c|}
\hline & smooth participation is observed. & $\begin{array}{l}\text { not be represented sufficiently. } \\
\text { The co-production part } \\
\text { succeeded in involving the most } \\
\text { vulnerable groups also, that } \\
\text { resulted soft progresses. }\end{array}$ \\
\hline $\begin{array}{l}\text { Relevance in the } \\
\text { future }\end{array}$ & $\begin{array}{l}\text { The project recognized and addressed } \\
\text { the one of the highest challenges in } \\
\text { the historical center: social } \\
\text { degradation. For the duration of the } \\
\text { project there was observed higher } \\
\text { inclusivity in the participant group, } \\
\text { however, it might be periodic, for the } \\
\text { duration of the project. }\end{array}$ & $\begin{array}{l}\text { The project has an enormous } \\
\text { impact on creating the political } \\
\text { group on power of the local } \\
\text { government. The interests of the } \\
\text { most vulnerable groups are } \\
\text { awaited to be presented in the } \\
\text { daily politics too. However, it } \\
\text { could not contribute to creating } \\
\text { communities or groups. }\end{array}$ \\
\hline $\begin{array}{l}\text { Relationship } \\
\text { between public } \\
\text { bodies and dwellers }\end{array}$ & $\begin{array}{l}\text { The School of San Donato, as a center } \\
\text { of the project had a special role in it. } \\
\text { The previously rather underestimated } \\
\text { institution received higher attention } \\
\text { by the residents in and out of the } \\
\text { historical centre. }\end{array}$ & $\begin{array}{l}\text { One of the most crucial } \\
\text { advancements of the } \\
\text { programme is the improved } \\
\text { relationship between public } \\
\text { bodies and residents. The } \\
\text { advocacy and the self- } \\
\text { representation of the most } \\
\text { vulnerable groups have been } \\
\text { strengthened. }\end{array}$ \\
\hline
\end{tabular}

\section{References}

Bovaird, T. (2007). Beyond Engagement and Participation: User and Community Coproduction of Public Services. Public Administration Review, 67(5), pp.846-860.

Brandsen, T. and Pestoff, V. (2006). Co-production, the third sector and the delivery of public services. Public Management Review, 8(4), pp.493-501.

Cornwall, A. (2008). Unpacking "Participation": models, meanings and practices. Community Development Journal, 43(3), pp.269-283.

David Harvey (1975). Social justice and the city. Baltimore, Ml.: Johns Hopkins Univ. Pr.

Joshi, A. and Moore, M. (2004). Institutionalised Co-production: Unorthodox Public Service Delivery in Challenging Environments. Journal of Development Studies, 40(4), pp.31-49.

Lefebvre, H. (1991). The production of space. Malden, Ma; Oxford: Blackwell.

Lemanski, C. (2017). Unequal citizenship in unequal cities: participatory urban governance in contemporary South Africa. International Development Planning Review, 39(1), pp.15-35.

Maciocco, G., Lutzoni, L. and Valentino, M. (2018). Strutture generative e nuclei di urbanità. Milano, Italy: Francoangeli.

Mitlin, D. (2008). With and beyond the state - co-production as a route to political influence, power and transformation for grassroots organizations. Environment and Urbanization, 20(2), pp.339-360.

Ostrom, E. (1996). Crossing the great divide: Coproduction, synergy, and development. World Development, 24(6), pp.1073-1087. 
Pieterse, E.A. (2008). City futures: confronting the crisis of urban development. London; New York; Capetown, South Africa: Zed Books; UCT Press.

Rawls, J. (1971). A theory of justice. Harvard University Press.

Soja, E.W. (20010). Seeking spatial justice. Minneapolis: Univ. Of Minnesota Press. 